\title{
Microwave-assisted Synthesis of a ZrC-SiC Nanocomposite by Carbothermal Reduction and its Effect on Mean Particle Size
}

\author{
Juan Pablo Yasnó Gaviria ${ }^{a}$, Ruth Herta Goldschmidt Aliaga Kiminamia * \\ ${ }^{a}$ Department of Materials Engineering, Federal University of São Carlos - UFSCAR, Rod. Washington \\ Luiz, km 235, 13565-905, São Carlos, SP, Brazil
}

Received: January 30, 2016; Revised: June 2, 2016; Accepted: July 15, 2016

\begin{abstract}
$\mathrm{ZrC}-\mathrm{SiC}$ nanopowders were prepared by carbothermal reduction of $\mathrm{ZrO}_{2}$ and $\mathrm{SiO}_{2}$ with carbon black in argon gas atmosphere, using microwave energy as an alternative heating source. The samples were characterized by XRD, SEM and BET surface area analysis. The results indicate that highly crystalline $\mathrm{ZrC}-\mathrm{SiC}$ composites with a mean particle size of about $80 \mathrm{~nm}$ can be synthesized at a relatively low temperature $\left(\sim 1420^{\circ} \mathrm{C}\right)$. Microwave-assisted heating to obtain the $\mathrm{ZrC}$-SiC nanopowders significantly reduces the synthesis time to only $40 \mathrm{~min}$ when compared with the long reaction times involved in conventional carbothermal reduction, which requires about 8 hours to obtain $\mathrm{ZrC}$ and 2 hours to obtain $\mathrm{SiC}$.
\end{abstract}

Keywords: carbothermal reduction, microwave, $\mathrm{ZrC}-\mathrm{SiC}$ nanopowder

\section{Introduction}

Zirconium carbide $(\mathrm{ZrC})$, a refractory transition metal carbide of considerable technological interest, exhibits the characteristic properties of metals and ceramics owing to the simultaneous presence of a mixture of ionic, covalent and metallic bonds in its $\mathrm{NaCl}$-type crystal structure ${ }^{1}$. These exceptional properties, which include ultra-high melting point $\left(3540{ }^{\circ} \mathrm{C}\right)$, good resistance to high-speed gas or particle erosion and good ablation resistance ${ }^{2}$, make $\mathrm{ZrC}$ suitable for many applications, such as cutting tools, wear resistant components, field emitters, thermophotovoltaic radiators and diffusion barrier coatings on nuclear particle fuels for the nuclear industry ${ }^{3}$. On the other hand, silicon carbide ( $\mathrm{SiC}$ ) is a ceramic already widely used, particularly as an abrasive and in composites used for high-temperature structural applications ${ }^{4}$, with potential applications in field emitters, FETs, NEMS devices, catalysts and microwave absorbers ${ }^{5}$. ZrC-SiC composites are promising UHTCs that should exhibit the combination of high melting temperature and high temperature mechanical properties of $\mathrm{ZrC}$ and the passivation quality of $\mathrm{SiC}$.

Some synthesis methods have been developed to obtain $\mathrm{ZrC}-\mathrm{SiC}$, namely, carbothermal reduction, in which the reactants are $\mathrm{Zr}(\mathrm{OPr})_{4}, \mathrm{TEOS}$ and $\mathrm{AcOH}^{4}, \mathrm{ZrSiO}_{4}$ and $\mathrm{C}^{6,7}$ or $\mathrm{ZrO}_{2}, \mathrm{SiO}_{2}$ and $\mathrm{C}^{7}$; in situ reaction, using Si powders and phenolic resin with $\mathrm{Zr}$ powders ${ }^{8}$ or $\left(3 \mathrm{ZrO}_{2} \cdot \mathrm{CO}_{2} \cdot \mathrm{H}_{2} \mathrm{O}\right)^{9}$ and polymer-derived ceramics, using $\mathrm{ZrC}$ and $\left[\mathrm{Si}(\mathrm{H})\left(\mathrm{CH}_{3}\right) \mathrm{CH}_{2}\right]_{n}{ }^{10}$. However, the carbothermal reduction of $\mathrm{ZrO}_{2} / \mathrm{SiO}_{2}$ is regarded as the most common method ${ }^{6}$ due to its simplicity and easy control of the composition.
The formation of $\mathrm{ZrC}$ from $\mathrm{ZrO}_{2}$ during the conventional carbothermal reduction is represented by following general reaction ${ }^{11}$ :

$$
\mathrm{ZrO}_{2}(\mathrm{~s})+3 \mathrm{C}(\mathrm{s}) \longrightarrow \mathrm{ZrC}(\mathrm{s})+2 \mathrm{CO}(\mathrm{g})
$$

This process can take place in three reaction steps ${ }^{12}$ : (a) formation of $\mathrm{CO}$ by a solid state reaction between $\mathrm{ZrO}_{2}$ and carbon particles with the subsequent formation of $\mathrm{ZrO}_{2-\mathrm{x}}$, (b) incorporation of carbon into the crystal lattice to form super-stoichiometric $\mathrm{ZrC}_{x} \mathrm{O}_{y}$, and (c) substitution of oxygen with carbon in $\mathrm{ZrC}_{\mathrm{x}} \mathrm{O}_{\mathrm{y}}$ to form $\mathrm{ZrC}$. Nucleation of $\mathrm{ZrC}_{\mathrm{x}} \mathrm{O}_{\mathrm{y}}$ may take place inside the oxide particles, according to the abovementioned reaction model ${ }^{12}$, or in amorphous carbon, as suggested in a recent study ${ }^{13}$. In a conventional furnace, the carbothermal reduction of $\mathrm{ZrO}_{2}$ and carbon requires relatively high temperatures and long exposure times to form $\mathrm{ZrC}$, e.g., $1460{ }^{\circ} \mathrm{C} / 12 \mathrm{~h}^{11}$ and $1750^{\circ} \mathrm{C} / 8 \mathrm{~h}^{14}$. On the other hand, the formation of $\mathrm{SiC}$ from $\mathrm{SiO}_{2}$ during conventional carbothermal reduction is represented by the following general reaction ${ }^{15}$ :

$$
\mathrm{SiO}_{2}(\mathrm{~s})+3 \mathrm{C}(\mathrm{s}) \longrightarrow \mathrm{SiC}(\mathrm{s})+2 \mathrm{CO}(\mathrm{g})
$$

This reaction consists of a two-step gas-solid reaction:

$$
\begin{aligned}
& \mathrm{SiO}_{2}(\mathrm{~s})+\mathrm{C}(\mathrm{s}) \longrightarrow \mathrm{SiO}(\mathrm{g})+\mathrm{CO}(\mathrm{g}) \\
& \mathrm{SiO}(\mathrm{g})+2 \mathrm{C}(\mathrm{g}) \longrightarrow \mathrm{SiC}(\mathrm{s})+\mathrm{CO}(\mathrm{g})
\end{aligned}
$$

This reaction is believed to be a $\mathrm{SiO}(\mathrm{g})-\mathrm{CO}(\mathrm{g})$ gas-gas reaction at $1600^{\circ} \mathrm{C}$ or higher, and is attributed to the $\mathrm{SiO}(\mathrm{g})$ $\mathrm{C}(\mathrm{s})$ gas-solid reaction at $1500{ }^{\circ} \mathrm{C}$ or lower, favoring the formation of powder ${ }^{5}$. In a conventional furnace, $\mathrm{SiC}$ can be 
synthesized above $1500{ }^{\circ} \mathrm{C} / \sim 2 \mathrm{~h}^{16}$, assuming that the overall reaction to form $\mathrm{ZrC}-\mathrm{SiC}$ by conventional carbothermal reduction corresponds to the sum of Equations (1) and (2) 6 :

$\mathrm{ZrO}_{2}(\mathrm{~s})+\mathrm{SiO}_{2}(\mathrm{~s})+6 \mathrm{C}(\mathrm{s}) \longrightarrow \mathrm{ZrC}(\mathrm{s})+\mathrm{SiC}(\mathrm{s})+4 \mathrm{CO}(\mathrm{g})(5)$

The results obtained by conventional heating indicate that long reaction times and high reaction temperatures are required, which translate into a high cost to synthesize these powders. Moreover, the particle size of these powders is at the micron and sub-micron scale ${ }^{11,14,16}$.

However, the use of microwave energy as an alternative heating source may solve the problems arising from conventional carbothermal reduction ${ }^{17-19}$. In microwave heating, the interactions between the microwaves and the molecular structure of the materials result in fast heating, a marked decrease in the activation energies of the reaction, and an increase in the diffusion rates of the process ${ }^{20}$. In most cases, when microwave energy is applied to carbothermal reduction reactions, it represents a simpler and faster route than the conventional one, also considering the greater adsorption in the case of C-containing materials ${ }^{7,15-22}$. In this work, an investigation was made into the synthesis of $\mathrm{ZrC}$ $\mathrm{SiC}$ nanocomposites by microwave-assisted carbothermal reduction and its effect on mean particle size. The use of microwaves as the energy source for the carbothermal reduction process is economically promising, very fast and relatively simple.

\section{Experimental Procedure}

Zirconia (ALDRICH, 99\%, particle size $<100 \mathrm{~nm}$ ), silica gel (High-purity grade, particle size $<100 \mathrm{~nm}$ ) and carbon black (particle size $<100 \mathrm{~nm}$ ), in a $\mathrm{Zr}$ :Si:C molar ratio of $1: 1: 6$, were stirred into isopropyl alcohol at $65^{\circ} \mathrm{C}$ for 30 minutes and then partially dried. The weights of the required reactants were calculated assuming that the overall reaction corresponds to Equation (5). The mass was extruded into pellets. The reaction system designed for the synthesis was based on a reaction system used to prepare $\mathrm{Al}_{2} \mathrm{O}_{3} / \mathrm{SiC}$ powders $^{22}$. About $1.5 \mathrm{~g}$ of pellets were weighed in a mullite/ alumina rectangular crucible, which was inserted into a low porosity ceramic tube, coated with refractory fiber to prevent heat loss, at the center of the oven cavity of a multimodal microwave applicator $(2.45 \mathrm{GHz}$, Cober, MS6K). The reactions were performed at $3 \mathrm{~kW}$ for reaction times in the range of 40-60 min. The temperature was measured using an infrared pyrometer (Raytek, RAYMA2SCSFL) positioned directly above the pellets, using a circular transparent quartz glass window placed at one end of the ceramic tube. The synthesized powders were deagglomerated in a mortar, yielding very fine dark samples.

The crystalline phases of the powders were determined from X-ray diffraction patterns recorded by a diffractometer operating with $\mathrm{Cu} \mathrm{K} \alpha$ radiation (XRD, Siemens, D5010) from $20^{\circ}$ to $80^{\circ}(2 \theta)$ and a scan step of $2 \% \mathrm{~min}$. The crystallite size (D) of the carbide phases was calculated from the reflection of the (111) plane (the highest intensity peak of $\mathrm{ZrC}$ and $\mathrm{SiC}$ ) of the XRD profile, in accordance with the Scherrer formula ${ }^{23}$ :

$$
\mathrm{D}=\mathrm{k} \lambda / \beta \cdot \cos \theta \quad(6)
$$

where $\mathrm{k}$ is a constant related to the crystallite shape, $\lambda$ is the X-ray wavelength, $\beta$ is the half-maximum breadth, and $\theta$ is the Bragg angle of the (111) plane. The specific surface area of the synthesized powders was measured by the BET method, based on $\mathrm{N}_{2}$ adsorption/desorption curves (Micromeritics, ASAP 2020), and the particle size (equivalent spherical diameter) was also determined by this technique, using the following equation:

$$
\mathrm{D}_{\mathrm{BET}}=6 / \rho \cdot \mathrm{S}_{\mathrm{BET}}
$$

where $D_{B E T}$ is the equivalent average diameter $(\mu \mathrm{m})$, $\mathrm{S}_{\mathrm{BET}}$ is the surface area determined by BET $\left(\mathrm{m}^{2} / \mathrm{g}\right)$, and $\rho$ is the density $\left(\mathrm{g} / \mathrm{cm}^{3}\right)$ of the powders. The powder density was determined using a helium pycnometer (Micromeritics, ACCUPYC 1330). Lastly, the morphology was examined by field emission scanning electron microscopy (FEG-SEM, Philips, XL30).

\section{Results and Discussions}

$\mathrm{X}$-ray diffraction (XRD) patterns of the products of the reactions in $\mathrm{ZrO}_{2}, \mathrm{SiO}_{2}$ and $\mathrm{C}$ mixtures obtained by microwave-assisted carbothermal reduction, applying a constant power of $3 \mathrm{~kW}$ for different reaction times, are presented in Figure 1. The XRD peaks of the initial mixture $\left(\mathrm{ZrO}_{2}+\mathrm{SiO}_{2}+\mathrm{C}\right)$, included for comparison, are all due to the monoclinic phase of $\mathrm{ZrO}_{2}$ (JCPDS 83-944), because there is no reaction between the starting materials $(\mathrm{t}=0 \mathrm{~min})$. It is worth noting that $\mathrm{SiO}_{2}$ and $\mathrm{C}$ phases do not appear due to their amorphous state. The powder synthesized at $3 \mathrm{~kW}$ for $40 \mathrm{~min}$ is composed mainly of $\mathrm{ZrC}$ (JCPDS 89-3829) and $\mathrm{SiC}$ (JCPDS 73-1708), indicating that the carbothermal reductions of $\mathrm{ZrO}_{2}$ and $\mathrm{SiO}_{2}$ were substantially completed. At the end of $40 \mathrm{~min}$, the reaction temperature reached $\sim 1420^{\circ} \mathrm{C}$. The temperature was measured using an infrared pyrometer (Raytek, RAYMA2SCSFL) positioned directly above the pellets, using a circular transparent quartz glass window placed at one end of the ceramic tube. This experimental assembly for precise measurement of the reaction temperature of the carbothermal reduction of $\mathrm{ZrC}-\mathrm{SiC}$ composites did not require the microwave irradiation to be interrupted, thus enabling data on the in situ reaction temperature to be recorded. This procedure differed from the one employed by Das et al. ${ }^{7}$, who used a shielded $\mathrm{Pt} / \mathrm{Rh}$ thermocouple in contact with the sample after interrupting the microwave irradiation. It is believed that the amorphous carbon reacts 
with the oxides and forms $\mathrm{SiC}$ and $\mathrm{ZrC}$, according to Equation (5). This formation of carbide phases, which is favored by raising the temperature to $1420^{\circ} \mathrm{C}$, can be attributed to the interaction between the electromagnetic field and the initial mixture $\left(\mathrm{ZrO}_{2}+\mathrm{SiO}_{2}+\mathrm{C}\right)$, which produces a microwave-induced electrical current in carbon particles due to their absorption properties. This process generates heat in the carbon particles (originating mainly from Joule losses), which is subsequently transferred to $\mathrm{SiO}_{2}$ and $\mathrm{ZrO}_{2}$ particles, favoring the $\mathrm{SiO}_{2} \rightarrow \mathrm{SiC}$ and $\mathrm{ZrO}_{2} \rightarrow \mathrm{ZrC}$ conversions described by Equations (1) and (2), respectively. The difference between the highest peak intensities corresponding to $\mathrm{ZrC}$ and $\mathrm{SiC}$ phases may be due to less $\mathrm{SiC}$ in the sample, possibly caused by the volatilization of $\mathrm{SiO}(\mathrm{g})$ during the reaction, as suggested in the conventional carbothermal reduction of zircon $\left(\mathrm{ZrSiO}_{4}\right)$ and activated carbon (carbothermal reduction in a conventional furnace), as follows :

$$
\begin{array}{r}
\mathrm{SiC}(\mathrm{s})+2 \mathrm{SiO}_{2}(\mathrm{~s}) \longrightarrow 3 \mathrm{SiO}(\mathrm{g})+\mathrm{CO}(\mathrm{g}) \quad(8) \\
3 \mathrm{SiC}(\mathrm{s})+2 \mathrm{ZrO}_{2}(\mathrm{~s}) \longrightarrow 2 \mathrm{ZrC}+3 \mathrm{SiO}(\mathrm{g})+\mathrm{CO}(\mathrm{g})
\end{array}
$$

Moreover, $\mathrm{SiC}$ also reduces $\mathrm{ZrC}_{\mathrm{x}} \mathrm{O}_{\mathrm{y}}^{4}$ :

$\mathrm{ZrC}_{\mathrm{x}} \mathrm{O}_{\mathrm{y}}(\mathrm{s})+\mathrm{SiC}(\mathrm{s}) \longrightarrow \mathrm{ZrC}(\mathrm{s})+\mathrm{SiO}(\mathrm{g})+\mathrm{CO}(\mathrm{g})$

Therefore, there is very likely a loss of $\mathrm{SiO}(\mathrm{g})$ in the outlet gas during the carbothermal reduction, given the continuous consumption of $\mathrm{SiC}$ via side reaction until the formation of $\mathrm{ZrC}$ is completed, as presented in Equations (9) and (10). The presence of traces, identified as $\mathrm{m}-\mathrm{ZrO}_{2}$ in Figure 1, may be attributed to the loss of material through the volatilization of gaseous species $(\mathrm{SiO}$ and $\mathrm{CO}$ ) in the outlet gas during the reduction reaction, leaving behind unreacted $\mathrm{ZrO}_{2}$. However, the amount of $\mathrm{m}-\mathrm{ZrO}_{2}$ is very small. Although the reaction time was increased to $50 \mathrm{~min}$ and to $60 \mathrm{~min}$, and the temperature to $1440{ }^{\circ} \mathrm{C}$ and $1450{ }^{\circ} \mathrm{C}$, respectively, the behavior pattern was very similar. According to the Scherrer equation ${ }^{23}$, the mean crystallite size of $\mathrm{ZrC}$ was approximately $35 \mathrm{~nm}$, while that of $\mathrm{SiC}$ was approximately $26 \mathrm{~nm}$. This indicates that almost pure $\mathrm{ZrC}-\mathrm{SiC}$ powders of nanometric crystallite size can be produced in a reaction time of less than 1 hour. Compared to the conventional carbothermal reduction, the current method has the advantage of involving a shorter reaction time, which can be attributed to the combination of nanoscale precursors and the microwave heating technique, as reported in the literature for other similar materials ${ }^{17,18}$.

Figure 2 shows the specific surface area and mean particle size of mixtures prepared in a 1:1:6 M ratio of $\mathrm{Zr}: \mathrm{Si}: \mathrm{C}$ at $3 \mathrm{~kW}$ for 40 to $60 \mathrm{~min}$, which contain $\mathrm{ZrC}$ and $\mathrm{SiC}$ as the majority phases, unlike the initial mixture. The relative surface area of the powder synthesized for $40 \min \left(1420^{\circ} \mathrm{C}\right)$ was 11.57 $\mathrm{m}^{2} / \mathrm{g}$. It was found that increasing the reaction time to 60 $\min \left(1450{ }^{\circ} \mathrm{C}\right)$ reduced the surface area of the synthesized powder to $9.29 \mathrm{~m}^{2} / \mathrm{g}$. This means that the partial melting of

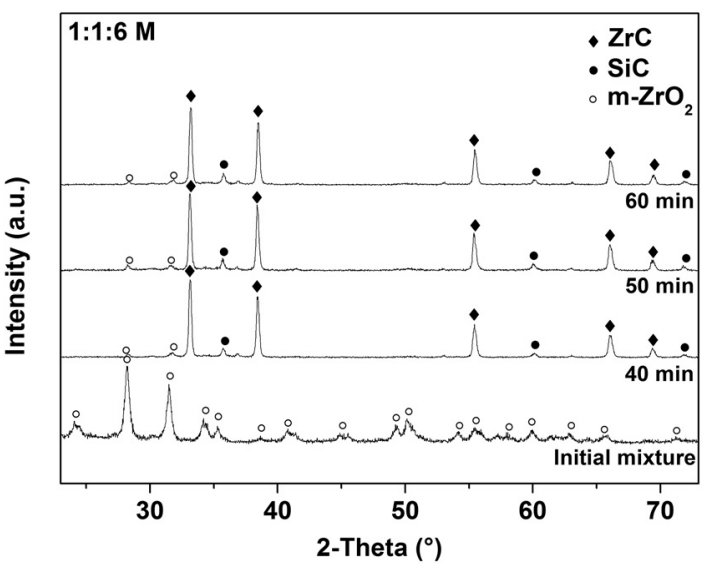

Figure 1: XRD patterns of mixtures prepared in a proportion of 1:1:6 $\mathrm{M}$ ratio of $\mathrm{Zr}: \mathrm{Si}: \mathrm{C}$ at $3 \mathrm{~kW}$ for different reaction times.

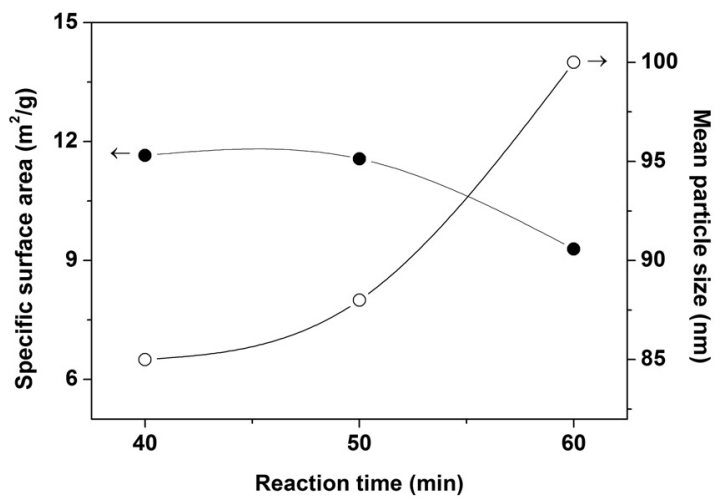

Figure 2: BET surface area and mean particle size vs. reaction time.

fine particles that form agglomerates in the pre-sintering process is more likely to occur in longer reaction times at high temperatures. This behavior is consistent with the results obtained in the synthesis of $\mathrm{SiC}$ by carbothermal reduction under fast microwave-induced heating ${ }^{15}$. The mean particle size of the powders was calculated based on the specific surface area (Equation(7)). Note that, as expected, the mean particle size of the synthesized powders increased from $85 \mathrm{~nm}$ in the powder synthesized for $40 \mathrm{~min}$ to $100 \mathrm{~nm}$ in the powder synthesized for $60 \mathrm{~min}$, in response to longer reaction times at high temperatures $\left(1420-1450{ }^{\circ} \mathrm{C}\right)$, favoring the partial fusion between primary crystalline particles to increase the overall particle size of the synthesized powders. The equivalent mean particle size of the $\mathrm{ZrC}-\mathrm{SiC}$ nanopowders ranged from 85 to $100 \mathrm{~nm}$, depending on the reaction time.

The particle size and morphology of $\mathrm{ZrC}-\mathrm{SiC}$ powders obtained by microwave-assisted carbothermal reduction for different reaction times are presented in Figure 3. Note that the morphology depicted in all the images is similar. Figure 3 reveals the presence of primary particles $(80-100$ $\mathrm{nm})$ that aggregate to form agglomerates $(<250 \mathrm{~nm})$. This agglomeration is caused by the tendency of very fine particles 

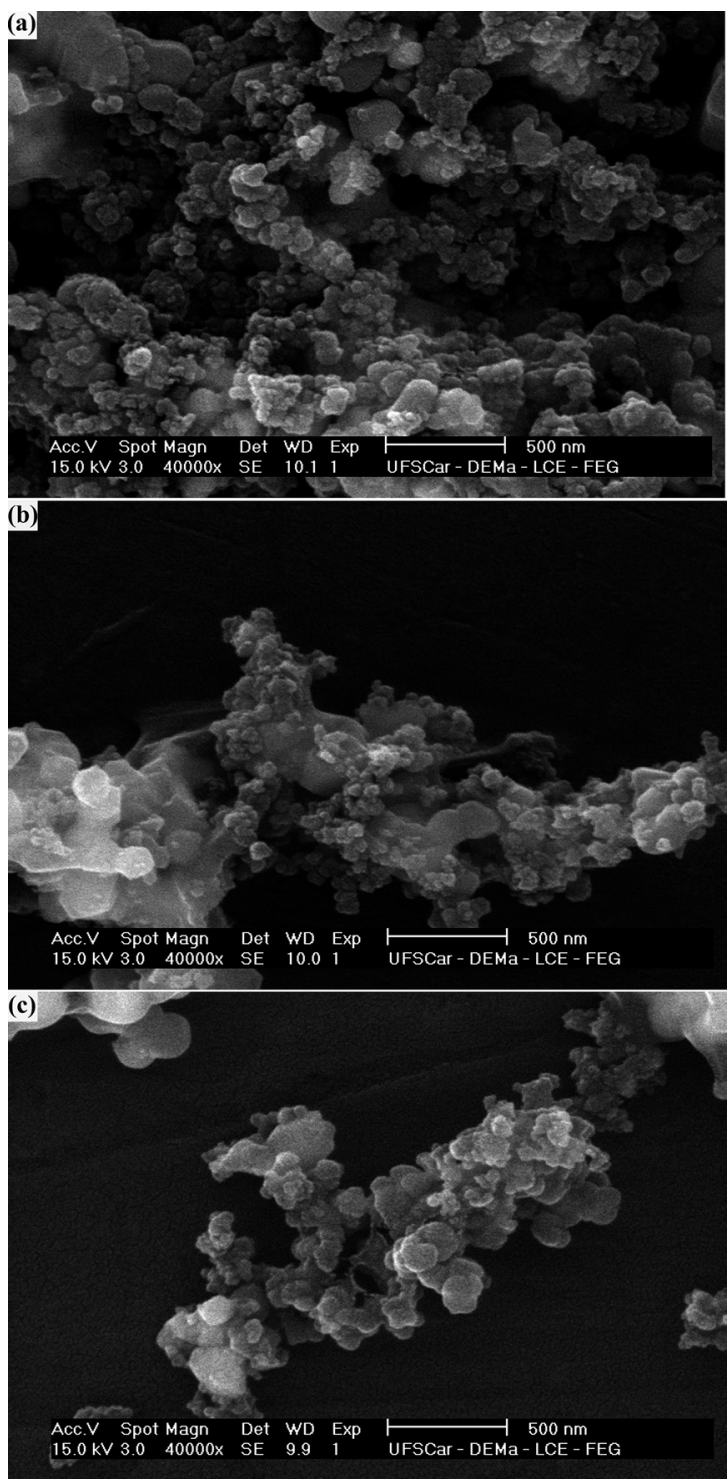

Figure 3. SEM micrographs of $\mathrm{ZrC}-\mathrm{SiC}$ powders prepared at 3 $\mathrm{kW}$ for (a) 40, (b) 50 and (c) 60 min, respectively.

to coalesce in response to surface charges, as reported by other researchers ${ }^{15}$. Increasing the reaction time caused the mean particle size to increase, resulting in the formation of some melt inclusions due to the high temperatures reached during the reaction, even at $3 \mathrm{~kW}$. The particle sizes are depicted in Figure 2. The nanometric particle sizes of the $\mathrm{ZrC}-\mathrm{SiC}$ powders synthesized by this method (in the aforementioned conditions) were smaller than those obtained by other researchers ${ }^{7}$ using a similar method, corresponding to $\mathrm{ZrC}-\mathrm{SiC}$ particle sizes at the micron scale.

These results confirm that carbothermal reduction is advantageous to synthesize $\mathrm{ZrC}-\mathrm{SiC}$ powders. The use of microwave power as a heating source proved to be efficient in synthesizing well crystallized $\mathrm{ZrC}$-SiC nanopowders, and the reaction remained close to the planned stoichiometry.
The overall reaction rate using microwave heating was very fast and yielded nanometric particles. Increasing the reaction time resulted in negligible increases in the mean particle size due to melting and agglomeration of primary particles. Compared to a similar $\operatorname{method}^{7}$, this approach reduced the particle size of the $\mathrm{ZrC}-\mathrm{SiC}$ powders from the micron to the nanometric scale.

\section{Conclusions}

In summary, microwave-assisted carbothermal reduction was used to produce well crystallized $\mathrm{ZrC}-\mathrm{SiC}$ nanocomposites of $\mathrm{ZrO}_{2}, \mathrm{SiO}_{2}$ and $\mathrm{C}$. An almost pure $\mathrm{ZrC}$-SiC composite was obtained at $3 \mathrm{~kW}$ of power in a reaction time of $40 \mathrm{~min}$ at $1420{ }^{\circ} \mathrm{C}$. Short reaction times used in the carbothermal reduction favored the production of $\mathrm{ZrC}-\mathrm{SiC}$ nanopowders with particles in the range of 80-100 $\mathrm{nm}$. Longer reaction times increased the overall particle size of $\mathrm{ZrC}-\mathrm{SiC}$ due to melting and agglomeration of primary particles. The advantage of this method over conventional carbothermal reduction is its shorter reaction time and lower temperature, in addition to producing nanometric products. Microwaveassisted carbothermal reduction is a promising route for the synthesis of $\mathrm{ZrC}-\mathrm{SiC}$ nanocomposites.

\section{Acknowledgement}

The authors gratefully acknowledge the financial support of CNPq (Brazil's National Council for Scientific and Technological Development) (Processes n 163424/2013-6 and 471441/2013-9).

\section{References}

1. Arya A, Carter EA. Structure, bonding, and adhesion at the $\mathrm{ZrC}(1$ $00) / \mathrm{Fe}\left(\begin{array}{lll}1 & 1 & 0\end{array}\right)$ interface from first principles. Surface Science. 2004;560(1-3):103-120.

2. Zhu Y, Cheng L, Ma B, Gao S, Feng W, Liu Y, et al. Calculation and synthesis of $\mathrm{ZrC}$ by CVD from $\mathrm{ZrCl}_{4}-\mathrm{C}_{3} \mathrm{H}_{6}-\mathrm{H}_{2}-\mathrm{Ar}$ system with high $\mathrm{H}_{2}$ percentage. Applied Surface Science. 2015;332:591-598.

3. Dong Z, Zhang X, Huang Q, Zhang J, Zuo X, Li W, et al. Synthesis and pyrolysis behavior of a soluble polymer precursor for ultra-fine zirconium carbide powders. Ceramics International. 2015;41(6):7359-7365.

4. El-Sheikh SM, Zaki ZI, Ahmed YMZ. In situ synthesis of ZrC/ $\mathrm{SiC}$ nanocomposite via carbothermic reduction of binary xerogel. Journal of Alloys and Compounds. 2014;613:379-386.

5. Wu R, Zhou K, Yue CY, Wei J, Pan Y. Recent progress in synthesis, properties and potential applications of $\mathrm{SiC}$ nanomaterials. Progress in Materials Science. 2015;72:1-60.

6. Setoudeh N, Welham NJ. Carbonitridation of mechanically activated mixtures of zircon and carbon. Journal of Alloys and Compounds. 2014;586:730-735. 
7. Das BP, Panneerselvam M, Rao KJ. A novel microwave route for the preparation of $\mathrm{ZrC}-\mathrm{SiC}$ composites. Journal of Solid State Chemistry. 2003;173(1):196-202.

8. Li Q, Dong S, Wang Z, Hu J, Wu B, Zhou H, et al. Fabrication of a $\mathrm{ZrC}-\mathrm{SiC}$ matrix for ceramic matrix composites via in-situ reaction and its application. Ceramics International. 2013;39(1):877-881.

9. Ma Y, Li S, Li Q, Wang Z, Shi G, Wu C, et al. Fabrication of $\mathrm{ZrC}-\mathrm{SiC}$ composites using zirconium salt as raw materials. Journal of Asian Ceramic Societies. 2014;2(4):317-321.

10. Lucas R, Davis CE, Clegg WJ, Pizon D, Babonneau F, Foucaud $\mathrm{S}$, et al. Elaboration of $\mathrm{ZrC}-\mathrm{SiC}$ composites by spark plasma sintering using polymer-derived ceramics. Ceramics International. 2014;40(10 Part A):15703-15709.

11. Maitre A, Lefort P. Solid state reaction of zirconia with carbon. Solid State Ionics. 1997;104(1-2):109-122.

12. Berger LM, Gruner W, Langholf E, Stolle S. On the mechanism of carbothermal reduction processes of $\mathrm{TiO}_{2}$ and $\mathrm{ZrO}_{2}$. International Journal of Refractory Metals and Hard Materials. 1999;17(1-3):235-243.

13. David J, Trolliard G, Gendre M, Maitre A. TEM study of the reaction mechanisms involved in the carbothermal reduction of zirconia. Journal of the European Ceramic Society. 2013;33(1):165-179.

14. Gendre M, Maître A, Trolliard G. Synthesis of zirconium oxycarbide $(\mathrm{ZrCxO} y)$ powders: Influence of stoichiometry on densification kinetics during spark plasma sintering and on mechanical properties. Journal of the European Ceramic Society. 2011;31(13):2377-2385.
15. Moshtaghioun BM, Poyato R, Cumbrera FL, Bernardi-Martin $\mathrm{S}$, Monshi A, Abbasi MH, et al. Rapid carbothermic synthesis of silicon carbide nano powders by using microwave heating. Journal of the European Ceramic Society. 2012;32(8):1787-1794.

16. Ebadzadeh T, Marzban-Rad E. Microwave hybrid synthesis of silicon carbide nanopowders. Materials Characterization. 2009;60(1):69-72.

17. Zhao Z, Chen F, Wang M, Zheng H. Synthesis of chromium carbide nanopowders via a microwave heating method. International Journal of Refractory Metals and Hard Materials. 2015;51:212-215.

18. Zhao Z. Microwave-assisted synthesis of vanadium and chromium carbides nanocomposite and its effect on properties of WC-8Co cemented carbides. Scripta Materialia. 2016;120:103-106.

19. Rao KJ, Vaidhyanathan B, Ganguli M, Ramakrishnan PA. Synthesis of inorganic solids using microwaves. Chemistry of Materials. 1999;11(4):882-895.

20. Fagury Neto E, Kiminami RHGA. Synthesis of silicon nitride by conventional and microwave carbothermal reduction and nitridation of rice hulls. Advanced Powder Technology. 2014;25(2):654-658

21. Fagury-Neto E, Kiminami RHGA. $\mathrm{Al}_{2} \mathrm{O}_{3} /$ mullite/ $\mathrm{SiC}$ powders synthesized by microwave-assisted carbothermal reduction of kaolin. Ceramics International. 2001;27(7):815-819.

22. Deksnys TP, Menezes RR, Fagury-Neto E, Kiminami RHGA. Synthesizing $\mathrm{Al}_{2} \mathrm{O}_{3} / \mathrm{SiC}$ in a microwave oven: A study of process parameters. Ceramics International. 2007;33(1):67-71.

23. Scherrer P. Bestimmung der Größe und der inneren Struktur von Kolloidteilchen mittels Röntgenstrahlen. Nachrichten von der Gesellschaft der Wissenschaften zu Göttingen, MathematischPhysikalische Klasse. 1918;1918:98-100. 